\title{
Thomas Ackermann
}

\section{Der Schutz des negativen Interesses}

\author{
Zur Verknüpfung von Selbstbindung und Sanktion im Privatrecht
}

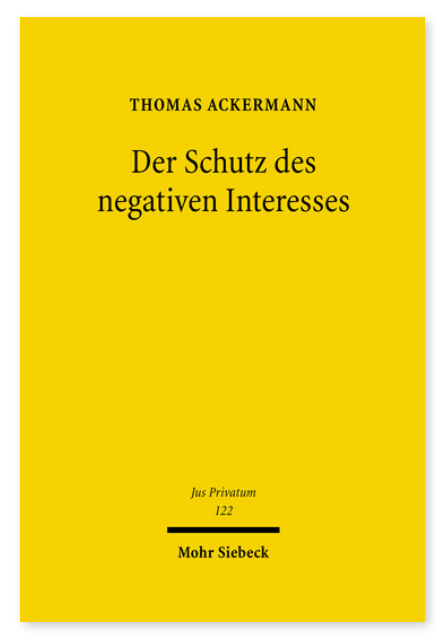

2007. XXII, 581 Seiten. JusPriv 122

ISBN 978-3-16-151199-8

DOI 10.1628/978-3-16-151199-8

eBook PDF $134,00 €$
Die Haftung auf das negative Interesse wird im deutschen Privatrecht weithin auf einen im Vertrauen, im Verkehrsinteresse oder schlicht im 'Gesetz', aber nicht in der privatrechtlichen Selbstbindung wurzelnden Tatbestand gestützt. Thomas Ackermann legt dar, dass diese Sicht weder rechtspolitisch legitim noch rechtsdogmatisch gefordert ist, und entwickelt die Pflicht zum Ersatz des negativen Interesses als Sanktion für vertragliche und außervertragliche Selbstbindungstatbestände. Die Neuinterpretation der Verknüpfung von Selbstbindung und Sanktion ermöglicht es, zahlreiche Problemlösungen zu verstehen, die, obwohl sie offenbar sachgerecht sind, nicht in ein von der konventionellen Auffassung geprägtes Haftungssystem passen. Das rechtspolitische Fundament dieser Weichenstellung wird im ersten Teil der Untersuchung durch den Entwurf einer marktfunktionalen Selbstbindungskonzeption gelegt, welche die ökonomischen Wertungen offen legen hilft, die seit den Anstößen durch Jhering und Fuller in der deutschen und in der anglo-amerikanischen Rechtsentwicklung wirksam geworden sind. Der zweite Teil entfaltet das hierauf gründende System des Schutzes des negativen Interesses im deutschen Recht. Neu geschaffene Regelungen wie § 284 BGB und angestammte Rechtsinstitute wie die c.i.c. werden dadurch erstmals bis ins Detail als Teil eines stimmigen Ganzen erschlossen.

Thomas Ackermann Geboren 1966; Studium der Rechtswissenschaften in Bonn und Cambridge; 1997 Promotion und 2004 Habilitation in Bonn; Inhaber des Lehrstuhls für Bürgerliches Recht, Europäisches und Internationales Wirtschaftsrecht an der Ludwig-Maximilians-Universität München.

Jetzt bestellen:

https://mohrsiebeck.com/buch/der-schutz-des-negativen-interesses-9783161511998?no_cache=1

order@mohrsiebeck.com

Telefon: +49 (0)7071-923-17

Telefax: +49(0)7071-51104 